Jorge Diaz-Garzon*, Pilar Fernandez-Calle, Aasne K. Aarsand, Sverre Sandberg, Abdurrahaman Coskun, Anna Carobene, Niels Jonker, Outi Itkonen, William A. Bartlett and Antonio Buno, on behalf of the European Federation of Clinical Chemistry and Laboratory Medicine Working Group on Biological Variation

\title{
Long-term within- and between-subject biological variation of 29 routine laboratory measurands in athletes
}

https://doi.org/10.1515/cclm-2021-0910

Received August 15, 2021; accepted November 9, 2021;

published online November 19, 2021

Abstract:

Objectives: Within- and between-subject biological variation (BV) estimates have many applications in laboratory medicine. However, robust high-quality BV estimates are lacking for many populations, such as athletes. This study aimed to deliver BV estimates of 29 routine laboratory measurands derived from a Biological Variation Data Critical Appraisal Checklist compliant design in a population of high-endurance athletes.

Methods: Eleven samples per subject were drawn from 30 triathletes monthly, during a whole sport season. Serum samples were measured in duplicate for proteins, liver enzymes, lipids and kidney-related measurands on an Advia2400 (Siemens Healthineers). After outlier and homogeneity analysis, within-subject $\left(\mathrm{CV}_{\mathrm{I}}\right)$ and

*Corresponding author: Jorge Díaz-Garzón, Laboratory Medicine Department, La Paz University Hospital, Paseo de la Castellana 261, 28046 Madrid, Spain, Phone: +34 917277 000, Fax: +34 917277 050, E-mail: jdgmarco@gmail.com. https://orcid.org/0000-0002-3171-1505 Pilar Fernandez-Calle and Antonio Buno, Laboratory Medicine Department, La Paz University Hospital, Madrid, Spain

Aasne K. Aarsand and Sverre Sandberg, Norwegian Porphyria Centre, Department of Medical Biochemistry and Pharmacology, Haukeland University Hospital, Bergen, Norway; and Norwegian Organization for Quality Improvement of Laboratory Examinations (NOKLUS), Haraldsplass Deaconess Hospital, Bergen, Norway Abdurrahaman Coskun, Department of Medical Biochemistry, Acibadem Mehmet Ali Aydınlar University, School of Medicine, Atasehir, Istanbul, Turkey

Anna Carobene, Laboratory Medicine, IRCCS San Raffaele Scientific Institute, Milan, Italy

Niels Jonker, Certe, Wilhelmina Ziekenhuis Assen, Assen, The Netherlands

Outi Itkonen, Endocrinology and Metabolism Laboratory, Helsinki University Hospital, Helsinki, Finland

William A. Bartlett, Undergraduate Teaching, School of Medicine, University of Dundee, Dundee, Scotland between-subject $\left(\mathrm{CV}_{\mathrm{G}}\right)$ biological variation estimates were delivered (CV-ANOVA and log-ANOVA, respectively) and a linear mixed model was applied to analyze the effect of exercise and health related variables.

Results: Most $\mathrm{CV}_{\mathrm{I}}$ estimates were similar or only slightly higher in athletes compared to those reported for the general population, whereas two- to three-fold increases were observed for amylase, ALT, AST and ALP. No effect of exercise and health related variables were observed on the $\mathrm{CV}_{\mathrm{I}}$ estimates. For seven measurands, data were not homogeneously distributed and BV estimates were therefore not reported.

Conclusions: The observation of higher $\mathrm{CV}_{\mathrm{I}}$ estimates in athletes than what has been reported for the general population may be related to physiological stress over time caused by the continuous practice of exercise. The BV estimates derived from this study could be applied to athlete populations from disciplines in which they exercise under similar conditions of intensity and duration.

Keywords: athletes; biological variation; endurance exercise; long-term period; routine laboratory measurands.

\section{Introduction}

Biological variation (BV) describes the fluctuation of a measurand around its homeostatic set point in steady-state conditions and is known as the within-subject $\mathrm{BV}\left(\mathrm{CV}_{\mathrm{I}}\right)$, whereas the variations between the homeostatic set points of different individuals is denoted the between-subject BV $\left(\mathrm{CV}_{\mathrm{G}}\right)$. BV estimates have many applications in laboratory medicine, and in clinical laboratories, BV data plays a central role. The most important applications include setting analytical performance specifications (APS) [1], interpreting serial results from consecutive samples from an individual by the reference change value (RCV) [2] and to determine personalized reference intervals so that an individual can have their results assessed against their own reference interval [3]. The BV approach is presently 
recommended as a model to set APS for many routinely used measurands [4].

BV has most often been studied in healthy populations [5], but data are also available from populations with different diagnoses e.g. diabetes or chronic kidney disease, for which the subject can be considered in a steady state despite their pathological condition [6]. Pregnancy has also been considered a physiological state that can influence the BV and where BV estimates can be delivered after adjusting for trends if present [7]. A high level of physical exercise, maintained over time, in an individual, could also influence BV estimates, but there are only a few BV studies that specifically address the effect of exercise $[8,9]$. The Biological Variation Data Critical Appraisal Checklist (BIVAC) provides a framework on how to design and execute a BV study to deliver reliable BV estimates [10]. To our knowledge, there are no BIVAC compliant BV studies performed in an athlete population. This study aimed to deliver monthly BV estimates of 29 routine laboratory measurands including proteins, liver enzymes, lipids and kidney-related measurands, applying a BIVAC compliant design in a population of well-characterized high-endurance athletes. Additionally, we aimed to evaluate the possible influence of specific factors related to exercise, health, and sampling intervals on the BV estimates.

\section{Materials and methods}

\section{Study population}

A flowchart depicting the timeline of recruitment and inclusion of study subjects and sample collections is provided in Figure 1. Thirty subjects (15 women, median age 36 years, range $19-53$ years) were recruited from three triathlon clubs in Madrid, Spain and fulfilled the following inclusion criteria: Healthy, age $>18$ years, $>13 \mathrm{~h}$ of training per week (including running, cycling and/or swimming), normal standard medical examination and normal results for a stress test supervised by a physician specialist in sports medicine. The latter included electrocardiogram, spirometry, and dynamometry with measured maximum oxygen intake $\left(\mathrm{VO}_{2} \max \right)$, anaerobic and aerobic threshold, maximum heart rate (HR) and maximum power $\left(\mathrm{P}_{\max }\right)$.

The study was approved by the host Institution Research Ethical Committee and Informed Consent was signed by all the participants.

\section{Sample collections}

Following the Røraas simulation [11] to assure adequate study power i.e. a confidence interval $(\mathrm{CI})$ width lower than $1 / 3$ * $\left(\mathrm{CV}_{\mathrm{I}}\right), 11$ serum samples per subject were collected monthly (January to November) on Saturday mornings between 8 and 10 am after $10 \mathrm{~h}$ fasting. Subjects were instructed to avoid a heavy dinner, to be out of competition for one week and to avoid high-intensity exercise the $24 \mathrm{~h}$ prior to sampling. High-intensity exercise was defined by a heart rate (HR) above $80 \%$ of the maximum HR. In connection with each sampling, the subjects completed a questionnaire about fasting, vitamin supplementation and diet changes, health status and use of medication, date of last competition, details on last training (time, type and intensity) and in females, date of last menstrual period.

All aspects of the preanalytical phase were standardized [10, 12]. Venous blood samples were collected after $15 \mathrm{~min}$ of seated resting, and always by the same phlebotomist. In the first, 4th and 9th collection points, samples were also drawn to verify the health status of the athletes and to evaluate the results against the exclusion criteria (Supplementary File and Table 1). The laboratory results excluded any chronic or acute disease that could influence the BV estimates.

The blood samples were centrifuged at $2,000 \mathrm{~g}$ for $10 \mathrm{~min}$, then serum samples were aliquoted and stored at $-80^{\circ} \mathrm{C}$, within $2 \mathrm{~h}$ after the blood collection.

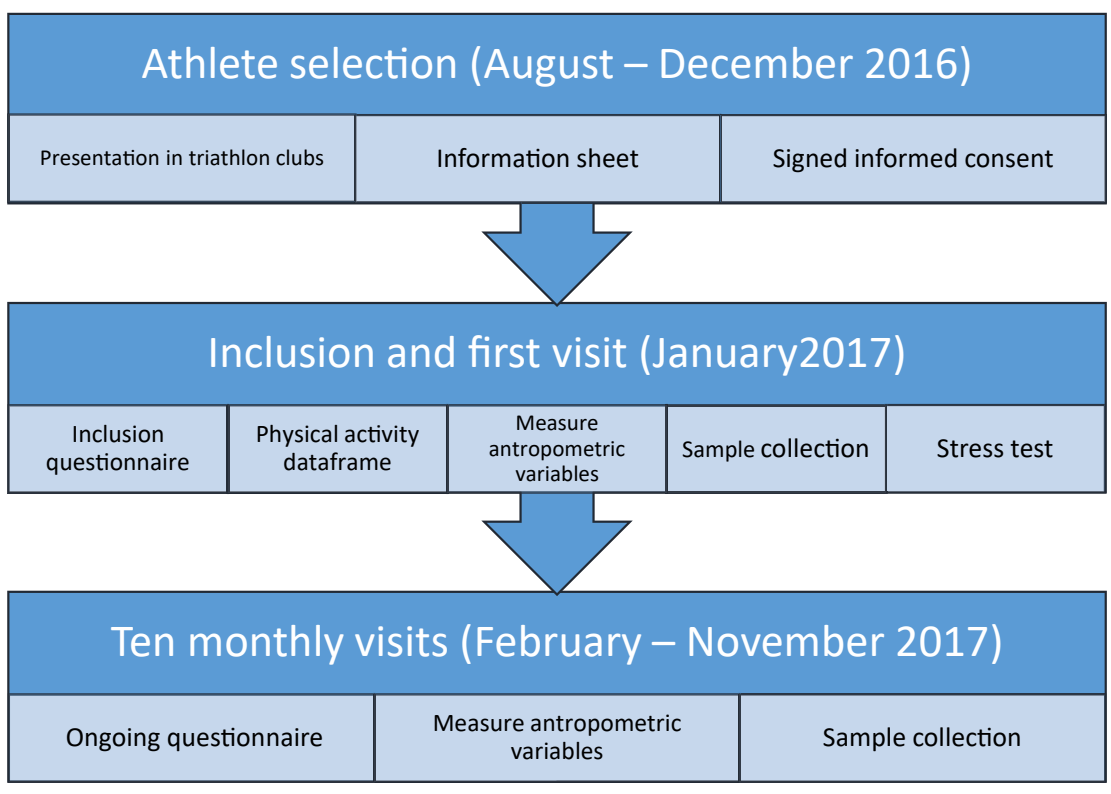

Figure 1: Flow chart of the study. Time-line of the sample collection and complementary tests. 


\section{Sample analysis}

All samples were analyzed in duplicate at the end of the collection period, within $2 \mathrm{~h}$ (after defrosting at room temperature and vortexing), on an Advia 2400 chemistry analyzer (Siemens Healthineers) for alkaline phosphatase (ALP), alanine aminotransferase (ALT), amylase, aspartate aminotransferase (AST), lactate dehydrogenase (LDH), creatinekinase (CK), total and direct bilirubin, gamma-glutamyltransferase (GGT), glucose, triglycerides, total cholesterol, HDL-cholesterol (HDL-C), LDL cholesterol (LDL-C), iron, ferritin, transferrin, magnesium, calcium, phosphate, potassium, chloride, sodium, total protein, albumin, urate, creatinine, urea and C-reactive protein (CRP). Information on analytical principles are provided in Supplementary Table 2. All samples from each subject were measured in the same run and with the same reagent lot. We used Liquid Assayed Multiqual (Bio-Rad) for internal quality control at two concentrations and participated in EQA programs for all measurands. All quality control results were within set limits.

\section{Statistical analysis}

Trend analysis was performed for each individual by plotting the results of each subject against the collection dates, as well as for the overall population. Also, the total result from all subjects was plotted to identify transversal trends related to preanalytical or analytical error, lot to lot shifts, seasonal variations etc. If the equation had an $\mathrm{r}$ coefficient greater than 0.75 and the $95 \%$ confidence interval of the slope did not include 0 , the trend was considered significant. If a significant trend was observed for a measurand in a particular subject, the data was excluded.

Outlier analysis was performed between replicates from the same sample and between the samples from the same subject, using the Cochran $\mathrm{C}$ test to assure the homoscedasticity for $\mathrm{CV}_{\mathrm{A}}$ and $\mathrm{CV}_{\mathrm{I}}[1,13]$. Reed's criterion was applied to assess differences between the athletes' mean values [14]. Thereafter, a CV-ANOVA was performed to deliver $\mathrm{CV}_{\mathrm{I}}$ estimates and after log-transforming the data, an ANOVA was applied to deliver $\mathrm{CV}_{\mathrm{G}}$ estimates [15]. For the calculations, we used RStudio Desktop 1.3.1093 and Microsoft Excel 2010.

We compared the BV estimates delivered by this study with previously published estimates from the general population and considered differences statistically significant when the 95\% CI did not overlap.

To explore the potential influence of different factors on the BV, we evaluated several parameters, as detailed below, by a linear mixed model (LMM) [16] by including these variables as fixed effects and all laboratory results from each individual. The $\mathrm{BV}$ estimates $\left(\mathrm{CV}_{\mathrm{I}}\right.$ and $\mathrm{CV}_{\mathrm{G}}$ ) and the CVA were the results from the LMM (random effects). We calculated the $\mathrm{CV}_{\mathrm{I}}$ with and without including the variable that was assessed for, following the script:

- Model without variable: $\log$ (measurand' results) (1|Subject) + (1| Subject:Visit)

- Model including the variable: $\log$ (measurand' results) $\sim$ Variable $+(1 \mid$ Subject $)+(1 \mid$ Subject:Visit $)$

The following fixed effects variables were used

- Health status: symptoms of disease registered in the week before sampling (yes/no).
- Sampling interval: time since the previous blood collection (number of days).

- Moderate intensity exercise performed in the $24 \mathrm{~h}$ before sampling (yes/no).

- The number of hours of endurance activity during the week before sampling (hours/week).

- Variables for duration: number of hours of endurance activity per week (h/w).

- Variables related to the intensity of exercise the week before sampling:

- (1) Average HR during all the training session classified by the percentage of the maximum HR, from T1 to T5: T1 $(<65 \%)$; T2 (65-80\%); T3 (80-90\%); T4 (95-98\%); T5 (100\%) [17].

- (2) Average of subjective perception of effort, recorded by the Borg scale: 0-4 sleep or inactive; 5-7 absence of effort; 8-9 very, very light; 10 very light; $11-12$ fairly light; $13-14$ somewhat hard, 15-16 hard; 17-19 very hard; 20 maximum effort [18].

A difference of more than $5 \%$ in the $\mathrm{CV}_{\mathrm{I}}$, after including the different variables in the LMM, was considered as significant. We performed an ANOVA between both models (including and without including the variable) to verify whether the differences were significant $(\mathrm{p}<0.05)$.

To calculate APS [1], RCV) [19], and the index of individuality (II) [20] the following formula were applied.

$-\mathrm{CV}_{\mathrm{A}}=0.5 \cdot\left(\mathrm{CV}_{\mathrm{I}}\right)$

- $\quad$ Bias $=0.5 \cdot\left(\mathrm{CV}_{\mathrm{I}}^{2}+\mathrm{CV}_{\mathrm{G}}^{2}\right)^{0.5}$

- $\quad \mathrm{RCV}=100 \% \cdot\left(\exp \left( \pm Z \cdot 2^{1 / 2} \cdot\left(\left(\mathrm{CV}_{\mathrm{LnA}}^{2}+\mathrm{CV}_{\mathrm{LnI}}^{2}\right)\right)^{1 / 2}\right)-1\right)$;

where $\mathrm{CV}_{\mathrm{Ln}}$ refers to ln-transformed data $=\left(\mathrm{Ln}\left(1+\mathrm{CV}^{2}\right)\right)^{1 / 2}$ and " $\mathrm{Z}$ " refers to the $Z$-score equal to the number of standard deviations appropriate for the selected probability.

- $\mathrm{II}=\mathrm{CV}_{\mathrm{I}} / \mathrm{CV}_{\mathrm{G}}$

\section{Results}

The anthropometric characteristics for the athletes are presented in Table 1 . The variables describing the aerobic performance of the athletes in the stress tests performed along the study are shown in Supplementary Table 3. The median values of $\mathrm{VO}_{2 \text { max }}$, an indicator of exercise performance, were close to the 90th percentile for the 30-40 years age range for the general population for both sexes $\left(51.7 \mathrm{~L} \mathrm{~kg}^{-1}\right.$ for male and $45.3 \mathrm{~L} \mathrm{~kg}^{-1}$ for females) [21]. The mean number of training sessions recorded per week was eight, on average 9.2 h of exercise per week (Supplementary Tables 4 and 5). Twenty-seven percent of the registered sessions were dedicated to cycling, 33\% running, 23\% swimming and the remaining $17 \%$ to other sports and the participants reported performing all three types of workout. The athletes mainly performed aerobic exercise. Generally, all participants performed training in a similar way, types of practiced sports, the distance and time spent, indicating 
Table 1: Median and interquartile range (IQR) of the anthropometric variables recorded during each of the athletes' visits according to gender.

\begin{tabular}{|c|c|c|c|c|}
\hline \multirow[b]{2}{*}{ Measurand } & \multicolumn{2}{|c|}{ Males $(n=15)$} & \multicolumn{2}{|c|}{ Females $(n=15)$} \\
\hline & Median & IQR & Median & IQR \\
\hline Age, years & 41 & $32-42$ & 34 & $30-39$ \\
\hline Height, m & 1.8 & $1.7-1.8$ & 1.7 & $1.6-1.7$ \\
\hline Weight, kg & 72.8 & $68.0-77.6$ & 57.0 & $54.9-60.7$ \\
\hline Fat mass, $\%$ & 11.2 & $9.0-13.0$ & 18.3 & $16.4-21.1$ \\
\hline Muscle mass, $\mathrm{kg}$ & 62.3 & $57.6-64.7$ & 45.5 & $41.7-47.1$ \\
\hline Bone mass, $\%$ & 3.3 & $3.0-3.4$ & 2.4 & $2.2-2.5$ \\
\hline Body mass index, $\mathrm{kg} \mathrm{m}^{-2}$ & 23.0 & $22.1-24.8$ & 21.1 & $20.2-22.1$ \\
\hline Water, \% & 64.9 & $63.5-66.5$ & 60.9 & $59.5-62.3$ \\
\hline
\end{tabular}

that the group was homogeneous concerning exercise profiles (Supplementary Table 5).

A total of 292 samples were collected, on average 9.7 samples per subject, providing a total of 584 results following the duplicate analysis. All the samples had the hemolysis, lipemia or icterus index below the assigned cutoff for interference. No trends were identified neither in the individual participants nor the overall study population. Thus, the subjects were considered in steady-state. No trends related to the season or analytical factors were observed.

For 22 of the 29 measurands, the analysis identified $3.7 \%$ (mean, range $0.1-10.1 \%$ ) of the data as outliers when assessed with homogeneity tests and these were thus eliminated. For the following measurands; total and direct bilirubin, CK, ferritin, GGT, iron and CRP, $20-84 \%$ of the results did not meet the Cochrane criteria. Thus, these data were not homogeneously distributed and using CV-ANOVA methods to deliver BV estimates are not appropriate. BV estimates were therefore not calculated for these measurands. We plotted the total variation of CK, ferritin and GGT (Figure 2) to illustrate the heterogeneity of results, as compared to measurands which were homogeneously distributed (sodium, chloride and potassium) (Figure 3).

The BV estimates of the 22 measurands, including mean concentration, total number of results and percentage of outliers are reported in Table 2.

Analysis for factors that potentially could be associated with BV did not identify any relative difference of the $\mathrm{CV}_{\text {I }}$ for sampling time, perceived exertion, intensity or duration of training in the week before sampling for any of the included measurands, with the relative differences of $\mathrm{CV}_{\mathrm{I}}$ with and without including the variable in the LMM

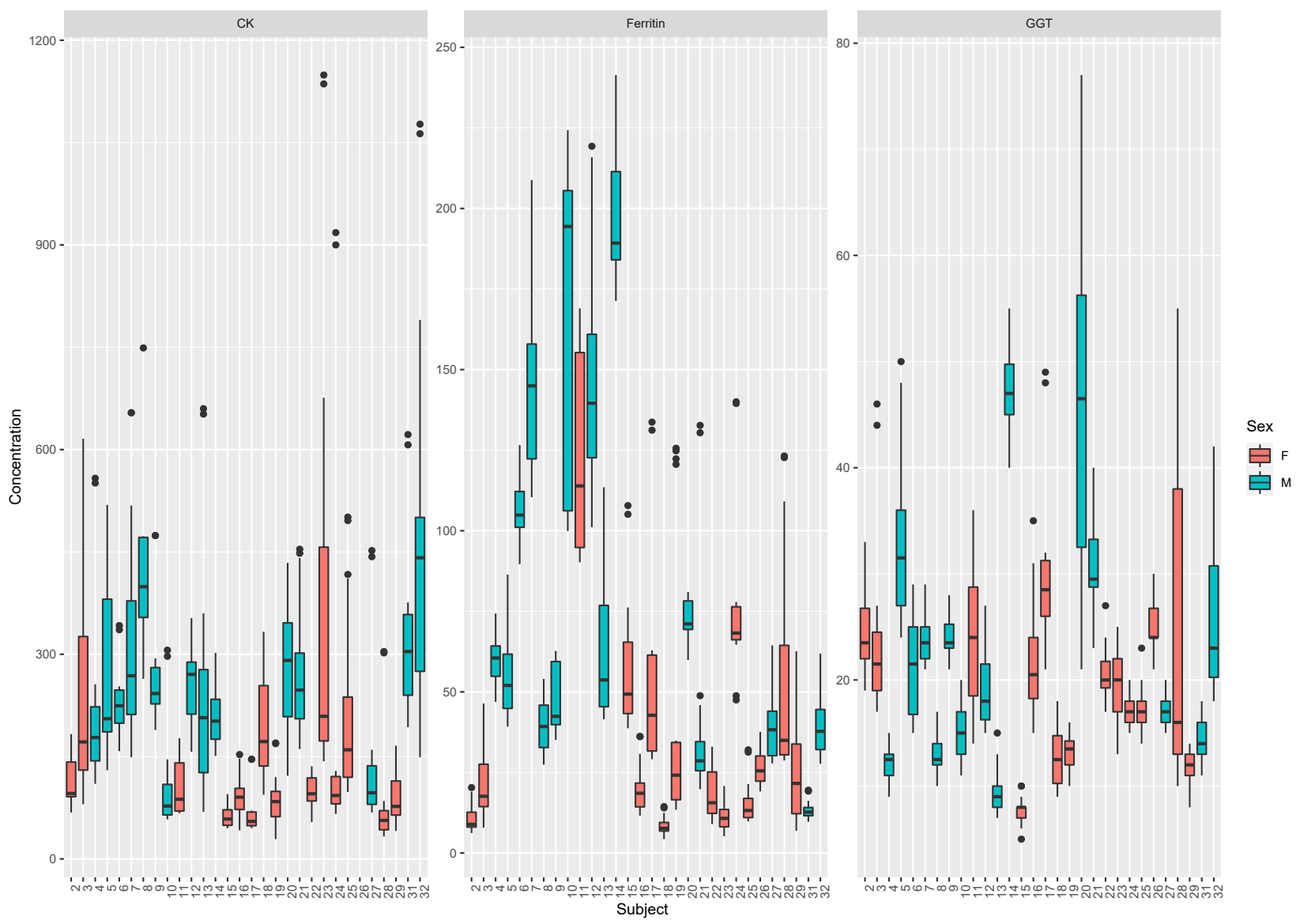

Figure 2: Non-homoscedastic measurands: $\mathrm{CK}(\mathrm{U} / \mathrm{L})$, ferritin $(\mathrm{ng} / \mathrm{mL})$ and $\mathrm{GGT}(\mathrm{U} / \mathrm{L})$ results for females (red) and males (blue) athletes. The boxes represent median and interquartile range from the crude data. 


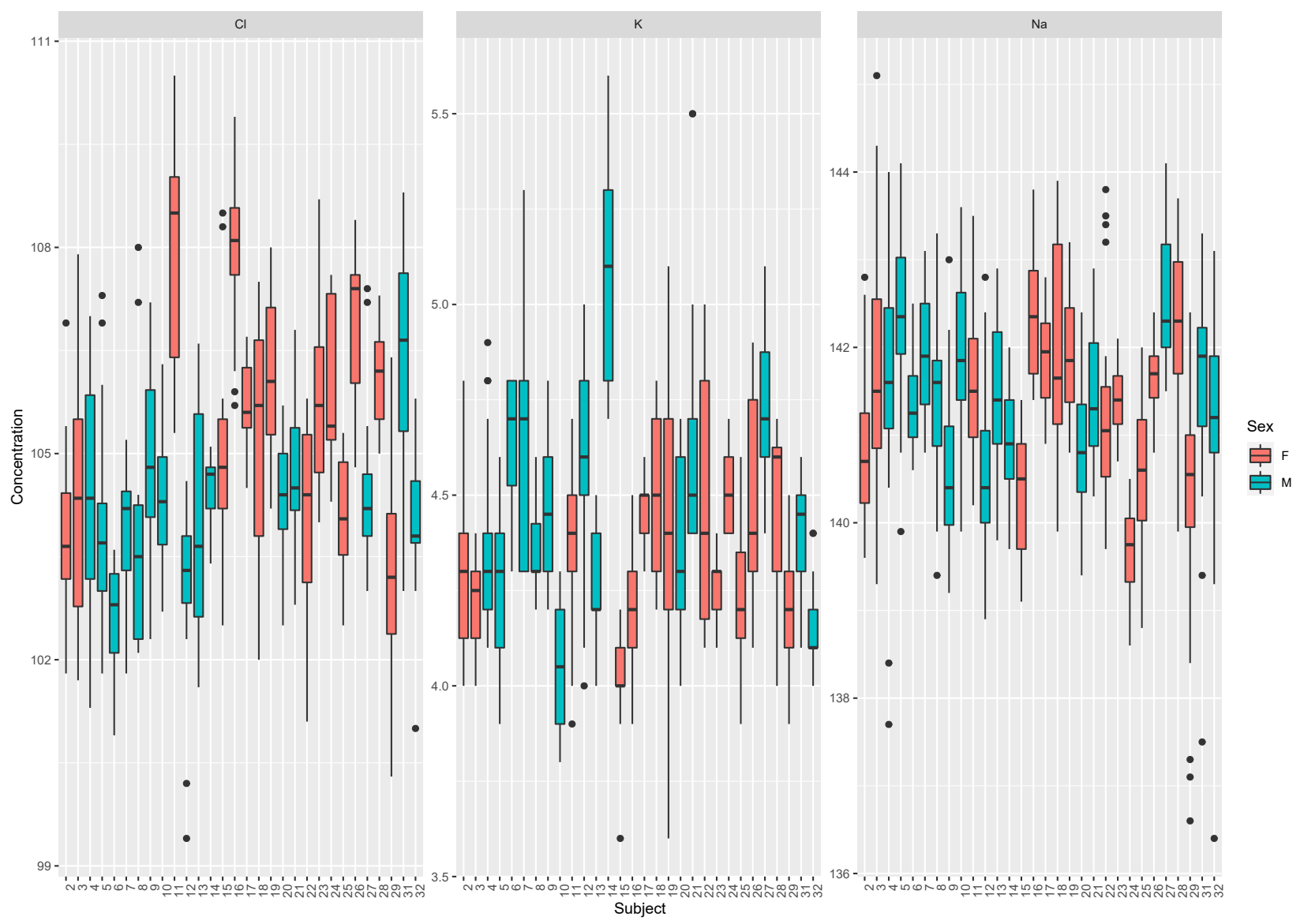

Figure 3: Homoscedastic measurands: chloride $(\mathrm{Cl})(\mathrm{mmol} / \mathrm{L})$, potassium $(\mathrm{K})(\mathrm{mmol} / \mathrm{L})$ and sodium $(\mathrm{Na})(\mathrm{mmol} / \mathrm{L})$ results for females $(\mathrm{red})$ and males (blue) athletes.

The boxes represent median and interquartile range from the crude data.

being less than $5 \%$ for all biomarkers (data not shown). APS, RCV and II for the measurands for which BV estimates were calculated are provided in Table 3.

\section{Discussion}

In this study on BV in athletes, the study subjects were assessed during 11 months, which represents a complete sports season, covering different phases (pre-season, quality training, competitions) and seasons (summer and winter). This reduces the risk of bias associated with e.g. training and competition seasons, which could have been an issue in a study of shorter duration. We collected blood samples monthly, with information related to physical performance and other variables that could potentially influence the results. Overall, only a few sampling sessions were missed (an average 9.7 samples/subject were included) indicating good adherence to the study.

Most of the previous publications on BV of biomarkers in athletes are short-term studies, where the samples were collected immediately post-exercise [22]. These studies report acute variations in e.g. white and red cell count, enzymes and electrolytes concentrations, all related to hemoconcentration occurring during exercise, with concentrations generally returning to baseline within $24 \mathrm{~h}$ $[23,24]$. An increase in enzyme activities also has been observed up to $24-72 \mathrm{~h}$ after exercise [25, 26]. In our study, we considered exercise as stable physiological stress maintained continuously, which may thus affect the derived BV estimates in this specific population. The data recorded on physical activity confirms that the study subjects performed constant training, and they are therefore representative and valid for such a BV study.

\section{BV estimates in athletes}

For 22 of the measurands, the percentage of outliers eliminated to fulfill statistical criteria (0.3-10.1\%) (Table 2) was comparable to those identified in previous studies in a healthy population for enzymes (1.2-14.2\%) [28] and 
Table 2: Number of subjects and included results, percentage of excluded outliers, mean and standard deviation: SD, analytical imprecision $\left(\mathrm{CV}_{\mathrm{A}}\right)$, within-subject $\left(\mathrm{CV}_{\mathrm{H}}\right)$ and between-subject $\left(\mathrm{CV}_{\mathrm{G}}\right)$ BV estimates and their $95 \%$ confidence intervals for 22 measurands.

\begin{tabular}{|c|c|c|c|c|c|c|c|c|c|c|}
\hline Measurand & Unit & $\begin{array}{r}\text { No. of } \\
\text { subjects }\end{array}$ & $\begin{array}{r}\text { No. of } \\
\text { included } \\
\text { results }\end{array}$ & Outliers, \% & Mean & SD & Gender & $\mathrm{CV}_{\mathrm{A}}$ & $\mathrm{CV}_{\mathrm{I}}(95 \% \mathrm{Cl})$ & $\mathrm{CV}_{\mathrm{G}}(95 \% \mathrm{Cl})$ \\
\hline Albumin & $\mathrm{mmol} / \mathrm{L}$ & 30 & 575 & 1.5 & 0.66 & 0.03 & $0 / 9$ & 1.1 & $3.2(2.9-3.5)$ & $3.8(2.9-5.1)$ \\
\hline ALT & $\mathrm{U} / \mathrm{L}$ & 30 & 535 & 8.4 & 15.2 & 4.5 & $0 / q$ & 23 & $27.6(24.2-31.4)$ & $30.7(23.1-42.6)$ \\
\hline Amylase & $\mathrm{U} / \mathrm{L}$ & 26 & 522 & 8.9 & 65.3 & 14.6 & $0 / q$ & 1.4 & $8.8(8.1-9.6)$ & $22.7(17.9-30.8)$ \\
\hline AST & $U / L$ & 28 & 525 & 10.1 & 25.3 & 6 & $0 / 9$ & 9.2 & $17.2(15.5-19.1)$ & $24.7(18.9-33.8)$ \\
\hline Calcium & $\mathrm{mmol} / \mathrm{L}$ & 30 & 575 & 1.5 & 2.35 & 0.05 & $0 / 9$ & 1.3 & $1.9(1.7-2.1)$ & $2.3(1.8-3.1)$ \\
\hline Chloride & $\mathrm{mmol} / \mathrm{L}$ & 30 & 570 & 2.4 & 104.9 & 1.3 & $0 / q$ & 0.4 & $1.2(1.1-1.3)$ & $1.2(0.9-1.6)$ \\
\hline HDL-C & $\mathrm{mmol} / \mathrm{L}$ & 29 & 554 & 5.1 & 1.53 & 0.27 & $0 / 9$ & 1.2 & $8.7(8-9.5)$ & $18.8(14.8-25.6)$ \\
\hline LDL-C & $\mathrm{mmol} / \mathrm{L}$ & 30 & 552 & 5.5 & 2.60 & 0.63 & o/o & 1.4 & $10.6(9.7-11.6)$ & $28(22.2-38.1)$ \\
\hline Total cholesterol & $\mathrm{mmol} / \mathrm{L}$ & 28 & 547 & 6.3 & 4.28 & 0.65 & $0 / q$ & 1.3 & $7(6.4-7.7)$ & $13.8(10.7-18.6)$ \\
\hline Creatinine & $\mathrm{mmol} / \mathrm{L}$ & 29 & 555 & 5 & 0.078 & 0.009 & $0 / 9$ & 3 & $4.5(4-5)$ & $13.3(10.5-17.8)$ \\
\hline \multirow[t]{2}{*}{ ALP } & $\mathrm{U} / \mathrm{L}$ & 29 & 561 & 3.9 & 60.2 & 13.7 & $\sigma^{+}$ & 1.5 & $7(6.2-8)$ & $15(10.7-22.8)$ \\
\hline & & & & & & & ㅇ & 1.3 & $9.5(8.5-10.9)$ & $28.3(20.7-44.9)$ \\
\hline Phosphate & $\mathrm{mmol} / \mathrm{L}$ & 30 & 576 & 1.4 & 1.16 & 0.10 & $0 / 9$ & 2.1 & $9.3(8.6-10.2)$ & $7.8(5.8-10.6)$ \\
\hline Glucose & $\mathrm{mmol} / \mathrm{L}$ & 30 & 569 & 2.6 & 4.22 & 0.24 & $\delta / 9$ & 1.2 & $5.9(5.4-6.5)$ & $5.2(5.4-6.5)$ \\
\hline LDH & $\mathrm{U} / \mathrm{L}$ & 28 & 542 & 7.2 & 170.9 & 20.9 & $\delta / q$ & 1 & $8.3(7.6-9.1)$ & $11.5(8.8-15.6)$ \\
\hline Magnesium & $\mathrm{mmol} / \mathrm{L}$ & 30 & 578 & 1 & 0.86 & 0.04 & $\delta / 9$ & 1.6 & $3.3(3-3.7)$ & $3.7(2.9-5)$ \\
\hline Potassium & $\mathrm{mmol} / \mathrm{L}$ & 29 & 546 & 6.5 & 4.4 & 0.2 & $\delta / 9$ & 0.6 & $4.6(4.2-5.1)$ & $4.3(3.3-5.9)$ \\
\hline Total protein & $\mathrm{g} / \mathrm{L}$ & 30 & 571 & 2.2 & 71 & 3 & o/? & 0.9 & $3.4(3.2-3.8)$ & $4.6(3.6-6.2)$ \\
\hline Sodium & $\mathrm{mmol} / \mathrm{L}$ & 30 & 569 & 2.6 & 141.4 & 0.7 & $\delta / 9$ & 0.4 & $0.5(0.4-0.6)$ & $0.4(0.3-0.6)$ \\
\hline Transferrin & $\mu \mathrm{mol} / \mathrm{L}$ & 30 & 578 & 1 & 33.82 & 4.45 & $0 / 9$ & 1.4 & $4.8(4.4-5.3)$ & $12.5(9.8-16.5)$ \\
\hline Triglycerides & $\mathrm{mmol} / \mathrm{L}$ & 29 & 540 & 7.5 & 0.70 & 0.14 & $\delta / 9$ & 2.3 & $19.3(17.7-21.1)$ & $22.2(16.9-30.3)$ \\
\hline Urate & $\mathrm{mmol} / \mathrm{L}$ & 30 & 573 & 1.9 & 0.29 & 0.06 & $0 / 9$ & 1 & $8.9(8.2-9.7)$ & $20.6(26.3-27.8)$ \\
\hline \multirow[t]{2}{*}{ Urea } & $\mathrm{mmol} / \mathrm{L}$ & 30 & 570 & 2.4 & 6.44 & 1.25 & $\widehat{0}$ & 1.3 & $12.6(11.2-14.4)$ & $10.3(6.9-16.1)$ \\
\hline & $\mathrm{mmol} / \mathrm{L}$ & & & & & & q & 1.4 & $16(14.7-18.2)$ & $20.9(14.7-34.2)$ \\
\hline
\end{tabular}

ALP, alkaline phosphatase; ALT, alanine aminotransferase; AST, aspartate aminotransferase; LDL-C, LDL cholesterol; HDL-C, HDL cholesterol; $\mathrm{LDH}$, lactate dehydrogenase.

substrates (0-5.6\%) [29, 30]. For total and direct bilirubin, CK, ferritin, GGT, iron and CRP, on the other hand, a high percentage of outliers, from $21-84 \%$, had to be removed to reach homoscedasticity, a requirement for ANOVA analysis. This highly variable behavior observed for these measurands, as illustrated in Figure 2, may indicate that in an athlete population, there is not a clear steady-state situation, but that factors related to their high-exertion exercise regime may influence the concentration of these markers. For CRP, results corresponding to the visits in which the subjects reported having been ill or having had an event that could elevate the acute phase reactants during the seven days before drawing blood were excluded from the data set. Nevertheless, if estimating $\mathrm{CV}_{\mathrm{I}}$ on the raw data set without removing outliers identified by statistical tests, this estimate was 10 times higher (data not shown) than those observed in the recently published EuBIVAS study in the general population [5] and twice as high as in other published studies in athletes. The higher variation in athletes and the lack of homogeneity of the data may be related to e.g. inflammatory processes linked to muscle damage during physical activity, distorting the steady-state situation. Therefore, BV estimates were not reported for total and direct bilirubin, CK, ferritin, GGT, iron and CRP.

Regarding differences between gender, urea and ALP were associated with higher $\mathrm{CV}_{\mathrm{I}}$ estimates in female than male athletes. This observation confirms the previous finding in the general population for urea [29]. For ALP and other enzymes, no differences between males and females have been reported for the general population [28], previous data on athletes are lacking.

\section{BV estimates in athletes vs. the general population}

Different BV estimates may be expected in athletes considering the continuous high-endurance exercise, compared to a general, more sedate population. Since a control group was not available for our study, estimates from studies from healthy subjects, derived from the EFLM BV database [31] 
Table 3: Desirable EPAs for imprecision $\left(\mathrm{CV}_{\mathrm{A}}\right)$, bias and index of individuality and reference change value for the interpretation of increases $\left(R C V_{\text {pos }}\right)$ and decreases $\left(R C V_{\text {neg }}\right)$ of serial results in athletes. The RCV has been calculated using $\mathrm{CV}_{\mathrm{A}}$ estimates derived from routine quality control in the Laboratory Medicine Department, La Paz University Hospital.

\begin{tabular}{|c|c|c|c|c|}
\hline Measurand & Gender & $\begin{array}{r}\text { APS } \\
\mathrm{CV}_{\mathrm{A}}, \%\end{array}$ & $\begin{array}{r}\text { APS } \\
\text { Bias/SE, \% }\end{array}$ & RCV (\%) neg/pos \\
\hline Albumin & $0 / 9$ & 1.6 & 1.2 & $-7.6 / 8.2$ \\
\hline ALT & $0 / 9$ & 13.8 & 10.3 & $-56.1 / 127.6$ \\
\hline Amylase & $\delta / q$ & 4.4 & 6.1 & $17.4 / 21$ \\
\hline AST & $\delta / q$ & 8.6 & 7.5 & $-36.9 / 58.6$ \\
\hline Calcium & $0 / q$ & 1 & 0.7 & $5.2 / 5.5$ \\
\hline Chloride & $\delta / 9$ & 0.6 & 0.4 & $-2.9 / 3$ \\
\hline HDL-C & $\delta / q$ & 4.4 & 5.2 & $-18.4 / 22.6$ \\
\hline LDL-C & $0 / 9$ & 5.3 & 7.5 & $-22 / 28.2$ \\
\hline Total cholesterol & $\delta / q$ & 3.5 & 3.9 & $-15.2 / 18$ \\
\hline Creatinine & $\delta / q$ & 2.3 & 3.5 & $-11.8 / 13.4$ \\
\hline \multirow[t]{2}{*}{ ALP } & $\sigma^{*}$ & 3.5 & 4.1 & $-15.4 / 18.8$ \\
\hline & q & 4.8 & 7.5 & $-20 / 25.1$ \\
\hline Phosphate & $\delta / q$ & 4.7 & 3 & $-20.9 / 26.5$ \\
\hline Glucose & $0 / 9$ & 3 & 2 & $-13.1 / 15$ \\
\hline LDH & o/q & 4.2 & 3.5 & $-17.6 / 21.4$ \\
\hline Magnesium & $0 / 9$ & 1.7 & 1.2 & $-8.2 / 8.9$ \\
\hline Potassium & o/q & 2.3 & 1.6 & $-10.2 / 11.4$ \\
\hline Total proteins & o/q & 1.7 & 1.4 & $-7.9 / 8.5$ \\
\hline Sodium & o/f & 0.3 & 0.2 & $-1.5 / 1.5$ \\
\hline Transferrin & $\delta / q$ & 2.4 & 3.3 & $-11 / 12.3$ \\
\hline Triglycerides & $0 / 9$ & 9.7 & 7.4 & $-36.1 / 56.5$ \\
\hline Urate & o/q & 4.5 & 5.6 & $-18.8 / 23.1$ \\
\hline \multirow[t]{2}{*}{ Urea } & $\sigma^{t}$ & 6.3 & 4.1 & $-25.4 / 34.1$ \\
\hline & q & 8 & 6.6 & $-30.9 / 44.8$ \\
\hline
\end{tabular}

ALP, alkaline phosphatase; ALT, alanine aminotransferase; AST, aspartate aminotransferase; LDL-C, LDL cholesterol; HDL-C, HDL cholesterol; LDH, lactate dehydrogenase.

and another athlete-specific study [8] are presented in Table 4 for comparison. However, differences should be interpreted with caution, considering that different factors related to study design and execution may influence the BV estimates derived from different studies. Of note, our study covered a full season and thus has a longer observation period than most of the other studies available for comparison. Regarding $\mathrm{CV}_{\mathrm{G}}$, no differences between athletes and the general population were observed for any measurand [31].

\section{Iron metabolism}

For transferrin, a higher $\mathrm{CV}_{\mathrm{I}}$ estimate was observed in our athlete population than that reported for healthy individuals (Table 4). Furthermore, ferritin and iron concentrations showed a big dispersion in the athlete population (Figure 2).
This fact could be explained by inflammation and the greater erythrocyte turnover in athletes due to phenomena associated with exercises such as oxidative stress, red blood cells mechanical breakdown and others [32, 33]. Higher ferritin $\mathrm{CV}_{\mathrm{I}}$ estimates have been reported from previous studies in athletes [34].

\section{Lipids}

The $\mathrm{CV}_{\text {I }}$ estimates for HDL-C, LDL-C and total cholesterol (Table 4) were slightly higher in athletes than those published for the healthy population [35]. A potential explanation may be that a greater demand and lipid mobilization involved in the metabolism as an energy resource during aerobic exercise, especially when carbohydrate availability is low. However, the study published by Nunes et al. [8] did not observe higher $\mathrm{CV}_{\mathrm{I}}$ for total cholesterol in athletes.

\section{Enzymes}

Higher $\mathrm{CV}_{\mathrm{I}}$ estimates were observed in the athlete population than those published for the adult general population [31], while the mean concentrations were similar [28]. The $\mathrm{CV}_{\mathrm{I}}$ for ALT activity was up to threefold increased, close to twofold for AST, LDH and ALP activity and slightly higher for amylase activity (Table 4). This finding could be related to the higher activity of bone (bone ALP) and liver release (damage to hepatocytes) (AST, ALT and ALP) [36], muscle release (AST) and hemolysis (LDH and AST) in athletes [27].

In the case of $\mathrm{CK}$, the great dispersion between athletes could be explained by a heterogeneous effect on the myocytes depending on the physical activity performed the days before sampling. Such an effect of physical exercise on CK has previously been described [25].

\section{Kidney related and other measurands}

For all the kidney related measurands, the $\mathrm{CV}_{\mathrm{I}}$ estimates derived from athletes and the healthy general population were similar [30, 31]. This is somewhat surprising for creatinine and urea, as one could expect higher values due to increased turnover of muscle protein (urea), variations in hydration status and a possible lower renal perfusion during prolonged and high-intensity exercises [37]. It may be that some changes occur immediately post-exercise, and that the concentrations of these biomarkers return to their basal state in the hours after sports practice [38], such has been described for other biomarkers [23, 24]. 
Table 4: Overview of within-subject $\left(\mathrm{CV}_{1}\right)$ and between-subject $\left(\mathrm{CV}_{\mathrm{G}}\right) \mathrm{BV}$ estimates in athletes, meta-analysis derived estimates from the EFLM Biological Variation Database and previously published data from athletes; ${ }^{a}$ Nunes et al. [8].

\begin{tabular}{|c|c|c|c|c|c|c|}
\hline \multirow[b]{2}{*}{ Measurand } & \multicolumn{2}{|c|}{ BV estimates in athletes } & \multicolumn{2}{|c|}{ EFLM BV database } & \multicolumn{2}{|c|}{$\begin{array}{c}\text { BV estimates from } \\
\text { other athletes } \\
\text { studies }\end{array}$} \\
\hline & $\mathrm{CV}_{\mathrm{I}}(\%)-(95 \% \mathrm{Cl})$ & $\mathrm{CV}_{\mathrm{G}}(\%)-(95 \% \mathrm{Cl})$ & $\mathrm{CV}_{\mathrm{I}}(\%)-(95 \% \mathrm{Cl})$ & $\mathrm{CV}_{\mathrm{G}}(\%)-(95 \% \mathrm{CI})$ & $\mathrm{CV}_{\mathrm{l}}, \%$ & $\mathrm{CV}_{\mathrm{G}}, \%$ \\
\hline Albumin & $3.2(2.9-3.5)$ & $3.8(2.9-5.1)$ & $2.6(2.2-3.9)$ & $5.1(2.2-3.9)$ & - & - \\
\hline ALP & $8.3(7.7-9.1)$ & $22.5(17.7-30.5)$ & $5.4(4.5-6.0)$ & $23.8(19.9-24.8)$ & - & - \\
\hline ALT & $27.6(24.2-31.4)$ & $30.7(23.1-42.6)$ & $10.1(9.3-15.6)$ & $29.3(28.0-38.4)$ & - & - \\
\hline Amylase & $7.8(7.2-8.6)$ & $26.3(20.4-35.9)$ & $6.6(6.2-7.1)$ & $30.2(25.7-36.9)$ & - & - \\
\hline AST & $17.2(15.5-19.1)$ & $24.7(18.9-33.8)$ & $9.5(9.4-13.5)$ & $20.4(19.8-23.8)$ & - & - \\
\hline Calcium & $1.90(1.70-2.12)$ & $2.34(1.79-3.15)$ & $1.8(1.7-2.3)$ & $2.7(1.1-3.8)$ & - & - \\
\hline Chloride & $1.21(1.10-1.32)$ & $1.16(0.88-1.57)$ & $1.1(0.9-1.4)$ & $1.3(1.2-1.4)$ & - & - \\
\hline Creatinine & $4.5(4.0-5.0)$ & $13.3(10.5-17.8)$ & $4.5(4.3-5.7)$ & $14.3(7.0-17.4)$ & $8.51^{a}$ & $11.9^{\mathrm{a}}$ \\
\hline Glucose & $5.9(5.4-6.5)$ & $5.2(5.4-6.5)$ & $5.0(4.1-12.0))$ & $8.1(2.7-10.8)$ & - & - \\
\hline HDL-C & $8.7(8.0-9.5)$ & $18.8(14.8-25.6)$ & $5.8(5.7-8.8)$ & $24.5(18.4-51.4)$ & - & - \\
\hline LDH & $8.3(7.6-9.1)$ & $11.5(8.8-15.6)$ & $5.2(4.9-5.6)$ & $12.5(10.8-14.7)$ & - & - \\
\hline LDL-C & $10.6(9.7-11.6)$ & $28.0(22.2-38.1)$ & $8.3(7.0-10.3)$ & $26.1(18.5-37.7)$ & - & - \\
\hline Magnesium & $3.31(3.01-3.65)$ & $3.74(2.88-5.04)$ & $2.9(1.6-5.9)$ & $5.8(0.7-8.5)$ & - & - \\
\hline Phosphate & $9.32(8.55-10.21)$ & $7.77(5.84-10.60)$ & $7.8(7.6-9.5)$ & $10.7(8.2-12.9)$ & - & - \\
\hline Potassium & $4.63(4.24-5.07)$ & $4.35(3.28-5.93)$ & $4.1(3.1-5.4)$ & $4.2(4.1-7.7)$ & - & - \\
\hline Sodium & $0.50(0.44-0.56)$ & $0.43(0.32-0.59)$ & $0.5(0.0-1.1)$ & $1.0(0.5-1.4)$ & - & - \\
\hline Total cholesterol & $7.0(6.4-7.7)$ & $13.8(10.7-18.6)$ & $5.3(5.1-6.4)$ & $16.3(14.0-17.4)$ & $5.4^{\mathrm{a}}$ & $15.8^{\mathrm{a}}$ \\
\hline Total protein & $3.4(3.2-3.8)$ & $4.6(3.6-6.2)$ & $2.6(2.3-2.7)$ & $4.6(2.8-5.7)$ & - & - \\
\hline Transferrin & $4.8(4.4-5.3)$ & $12.5(9.8-16.5)$ & $3.9(3.4-5.8)$ & $13.9(12.1-16.4)$ & - & - \\
\hline Triglycerides & $19.3(17.7-21.1)$ & $22.2(16.9-30.3)$ & $20.2(19.0-21.7)$ & $36.9(23.6-40.3)$ & $24.0^{\mathrm{a}}$ & $36.6^{\mathrm{a}}$ \\
\hline Urate & $8.9(8.2-9.7)$ & $20.6(26.3-27.8)$ & $8.3(7.9-8.8)$ & $23.6(20.4-27.5)$ & $12.1^{\mathrm{a}}$ & $20^{\mathrm{a}}$ \\
\hline Urea & $14.3(13.2-15.7)$ & $20.4(16-27.9)$ & $13.9(9.5-14.4)$ & $20.3(1.1-22.5)$ & $14.4^{\mathrm{a}}$ & $20.0^{\mathrm{a}}$ \\
\hline
\end{tabular}

ALP, alkaline phosphatase; ALT, alanine aminotransferase; AST, aspartate aminotransferase; LDL-C, LDL cholesterol; HDL-C, HDL cholesterol; $\mathrm{LDH}$, lactate dehydrogenase.

The $\mathrm{CV}_{\mathrm{I}}$ estimates for albumin and total proteins were slightly higher than those observed in the healthy population; which may be related to these measurands being altered with variations in plasma volume induced by exercise [39]. The $\mathrm{CV}_{\mathrm{I}}$ estimates of glucose were also higher than that reported in the literature [31]. Although sport helps maintain a better glycemic control in the individual [40], the fact that carbohydrates are one of the main energy resources in demand during exercise, which drives to consumption and resynthesis of glycogen [41], could induce a greater variation in athletes. Based on the LMM, we could not demonstrate that the variables related to exercise, health status or sampling interval influenced the $\mathrm{CV}_{\mathrm{I}}$ estimates in athletes. This suggests that the higher $\mathrm{CV}_{\mathrm{I}}$ estimates in athletes could be related to the condition of sustained physiological stress over time due to the continuous practice of exercise, however, further analysis of these data are required.

\section{Reference change value, index of individuality and analytical performance specifications}

The enzymes AST, amylase, ALP and LDH have a low II $(<0.6)$, indicating that they are good candidates for the application of RCV when monitoring in individual with laboratory test results over time. A high individuality was also observed in the measurands related to lipid metabolism (total cholesterol, HDL-C, LDL-C), which is why the use of the RCV for monitoring lipids in athletes is highly recommended (Table 3). For the application of the RCV, each laboratory should apply its own CVA to be applied in athletes tested outside of acute exertion. APS for these measurands in athletes would be, generally, more permissive, in particular for enzymes (AST and ALT). BV estimates derived from athletes in this study could help to set APS in both clinical laboratories providing health 
services to athletes, the accredited laboratories of the World Anti-doping Agency (WADA) network and the organizations that audit these laboratories [42].

\section{Study limitations}

In our study, the athletes varied in their exercise regimen. Ideally, a more standardized approach would be preferable, where all athletes followed the same setup, this was, however, practically difficult to achieve. Furthermore, an inclusion criterion was that athletes should train at least $13 \mathrm{~h}$ per week. Our data indicate that this was not achieved, however, a number of athletes reported not registering all exercise session throughout the study. The ANOVA models depend on variances being homogeneously distributed for the resulting mean $\mathrm{BV}$ estimates to be representative of the population. In our study, this lacked for seven measurands and BV data were therefore not reported for these. It may be argued that the derivation of BV in athletes may be problematic, due to the difficulty to reliably differentiate physiology from pathophysiology. Further study of our data, for these in homogeneously distributed as well as for the other measurands, by e.g. Bayesian models, which provide individual within-participant BV estimates, would be helpful to better understand the effect of exercise in athletes and its potential effect on the derived BV estimates [26]. We have compared our data derived from our athlete population with meta-analysis derived global estimates published in the EFLM BV Database. The inclusion of a control group in our study, consisting of non-athletes, would have provided better grounds for assessing differences between athletes and the general population.

\section{Conclusions}

We found that most of the BV estimates were similar or only slightly higher in athletes than those reported for the general population. However, greater differences were observed for amylase, ALT, AST and ALP. We were not able to demonstrate a clear influence of factors related to exercise and athletes' state of healthy influenced the $\mathrm{CV}_{\mathrm{I}}$ estimates, indicating that sustained physiological stress overtime during the practice of exercise may translate into higher $\mathrm{CV}_{\mathrm{I}}$ estimates. However, further studies must be performed, using different strategies such as the Bayesian approach, to understand the effect that some factors related to exercise could have over the BV. The BV estimates derived from this study could be applied to athlete populations with similar characteristics as the cohort included and from disciplines in which they exercise under similar conditions of intensity (aerobic exercise) and duration (medium-long). The APS derived from this study are equivalent or even more permissive than those derived from the general population for most of the studied biomarkers.

Acknowledgments: We would like to thank the voluntary athletes, Marlins Triathlon Madrid Club, Dr. Javier Sanguino and Dr. Juan José Rios Blanco for collaborating and giving support to the study because without them, this project would not be realized. We also thank the Hospital La Paz Research Foundation for the Dr. Luis Álvarez Grant that supported the project.

Research funding: Dr. Luis Álvarez Grant 2017 from Hospital La Paz Research Foundation

Author contributions: All authors have accepted responsibility for the entire content of this manuscript and approved its submission.

Competing interests: Authors state no conflict of interest. Informed consent: Informed consent was obtained from all individuals included in this study.

Ethical approval: The study was approved by University Hospital La Paz Research Ethical Committee (PI-2357).

\section{References}

1. Fraser CG. Biological variation in clinical chemistry. Arch Pathol Lab Med 1992;116:916-23.

2. Røraas T, Støve B, Petersen PH, Sandberg S. Biological variation: the effect of different distributions on estimated within-person variation and reference change values. Clin Chem 2016;62:725-6.

3. Coşkun A, Sandberg S, Unsal I, Cavusoglu C, Serteser M, Kilercik $M$, et al. Personalized reference intervals in laboratory medicine: a new model based on within-subject biological variation. Clin Chem 2021;67:374-84.

4. Sandberg S, Fraser CG, Horvath AR, Jansen R, Jones G, Oosterhuis $W$, et al. Defining analytical performance specifications: consensus statement from the 1st strategic conference of the European Federation of Clinical Chemistry and Laboratory Medicine. Clin Chem Lab Med 2015;53:833-5.

5. Carobene A, Aarsand AK, Bartlett WA, Coskun A, Diaz-Garzon J, Fernandez-Calle $P$, et al. The European Biological Variation Study (EuBIVAS): a summary report. Clin Chem Lab Med 2022;60: 505-17.

6. Carlsen S, Petersen PH, Skeie S, Skadberg O, Sandberg S. Within subject biological variation of glucose and HbA1c in healthy persons and in type 1 diabetes patients. Clin Chem Lab Med 2011; 49:1501-7.

7. Kristoffersen AH, Petersen PH, Røraas T, Sandberg S. Estimates of within-subject biological variation of protein $\mathrm{C}$, antithrombin, 
protein S free, protein S activity, and activated protein C resistance in pregnant women. Clin Chem 2017;63:898-907.

8. Nunes L, Brenzikofer R. Reference change values of blood analytes from physically active subjects. Eur J Appl Physiol 2010; 110:191-8.

9. Bagger M, Petersen H, Pedersen K. Biological variation in variables associated with exercise training. Int J Sports Med 2003;24:433-40.

10. Aarsand AK, Røraas T, Fernandez-Calle P, Ricos C, Díaz-Garzón J, Jonker $\mathrm{N}$, et al. The biological variation data critical appraisal checklist: a standard for evaluating studies on biological variation. Clin Chem 2018;64:501-14.

11. Røraas T, Petersen PH, Sandberg S. Confidence intervals and power calculations for within-person biological variation: effect of analytical imprecision, number of replicates, number of samples, and number of individuals. Clin Chem 2012;58:1306-13.

12. Bartlett WA, Braga F, Carobene A, Coşkun A, Prusa R, FernandezCalle P. A checklist for critical appraisal of studies of biological variation. Clin Chem Lab Med 2015;53:879-85.

13. Cochran WG. The distribution of the largest of a set of estimated variances as a fraction of their total. Ann Hum Genet 1941;11: 47-52.

14. Dixon WJ. Processing data for outliers. Biometrics 1953;9:74-89.

15. Røraas T, Støve B, Petersen PH, Sandberg S. Biological variation: the effect of different distributions on estimated within-person variation and reference change values. Clin Chem 2016;62: 725-36.

16. Bates D, Machler M, Bolker BM, Walker SC. Fitting linear mixed-effects models using Ime4. Available from: https://cran.r-project.org/web/packages/Ime4/vignettes/ Imer.pdf [Accessed 01 Oct 2021].

17. Pallarés J, Morán-Navarro R. Methodological approach to the cardiorespiratory endurance training. J Sport Health Res 2012;4: 119-36.

18. Borg GA. Psychophysical bases of perceived exertion. Med Sci Sports Exerc 1982;14:377-8.

19. Fraser CG, Harris EK. Generation and application of data on biological variation in clinical chemistry. Crit Rev Clin Lab Sci 1989;27:409-37.

20. Fraser CG, Sandberg S. Biological variation. In: Rifai N, Horvath AR, Wittwer CT, editors. Tietz textbook of clinical chemistry and molecular biology, 6th ed.; 2017:157-70 pp.

21. Vainshelboim B, Arena R, Kaminsky LA, Myers J. Reference standards for ventilatory threshold measured with cardiopulmonary exercise testing: the Fitness registry and the importance of exercise: a national database. Chest 2020;157: 1531-7.

22. Röcker L, Kiesewetter H. Effect of physical exercise on laboratory test results. In: Thomas L, editor. Frankfurt: Clinical Laboratory Diagnostics 2020. Available from: https://www.clinicallaboratory-diagnostics-2020.com/k51.html [Accessed 15 Nov 2021].

23. Alis R, Sanchis-Gomar F, Primo-Carrau C, Lozano-Calve S, Dipalo $M$, Aloe $R$, et al. Hemoconcentration induced by exercise: revisiting the Dill and Costill equation. Scand J Med Sci Sports 2015;25:630-7.

24. Boone C, Hoffman J, Gonzalez A, Jajtner A, Townsend J, Baker K, et al. Changes in plasma aldosterone and electrolytes following high-volume and high-intensity resistance exercise protocols in trained men. J Strength Cond Res 2016;30:1917-23.

25. Lippi G, Schena F, Montagnana M, Salvagno GL, Guidi GC. Influence of acute physical exercise on emerging muscular biomarkers. Clin Chem Lab Med 2008;46:1313-8.

26. Symanski JD, McMurray RG, Silverman LM, Smith BW, Siegel AJ. Serum creatine kinase and CK-MB isoenzyme responses to acute and prolonged swimming in trained athletes. Clin Chim Acta 1983;129:181-7.

27. Røraas T, Sandberg S, Aarsand AK, Støve B. A Bayesian approach to biological variation analysis. Clin Chem 2019;65: 995-1005.

28. Carobene A, Røraas T, Sølvik UØ, Sylte MS, Sandberg S, Guerra E, et al. Biological variation estimates obtained from 91 healthy study participants for 9 enzymes in serum. Clin Chem 2017;63: 1141-50.

29. Aarsand AK, Díaz-Garzón J, Fernandez-Calle P, Guerra E, Locatelli M, Bartlett WA. The EuBIVAS: within- and between-subject biological variation data for electrolytes, lipids, urea, uric acid, total protein, total bilirubin, direct bilirubin, and glucose. Clin Chem 2018;64:1380-93.

30. Carobene A, Marino I, Coşkun A, Serteser M, Unsal I, Guerra E, et al. The EuBIVAS project: within- and between-subject biological variation data for serum creatinine using enzymatic and alkaline picrate methods and implications for monitoring. Using enzymatic and alkaline picrate methods and implications for monitoring. Clin Chem 2017;63:1527-36.

31. Aarsand AK, Fernandez-Calle P, Webster C, Coskun A, Gonzales-Lao E, Diaz-Garzon J, et al. The EFLM biological variation database [Online]. Available from: https://biologicalvariation. eu/[Accessed 06 Jun 2021].

32. Schmidt W, Maassen N, Trost F, Böning D. Training induced effects on blood volume, erythrocyte turnover and haemoglobin oxygen binding properties. Eur J Appl Physiol Occup Physiol 1988;57:490-8.

33. Clénin G, Cordes $M$, Huber A, Schumacher YO, Noack $P$, Scales J, et al. Iron deficiency in sports-definition, influence on performance and therapy. Swiss Med Wkly 2015;145: w14196.

34. Malcovati L, Pascutto C, Cazzola M. Hematologic passport for athletes competing in endurance sports: a feasibility study. Haematologica 2003;88:570-81.

35. Díaz - Garzón J, Fernández-Calle P, Minchinela J, Aarsand AK, Bartlett WA. Aslan B Biological variation data for lipid cardiovascular risk assessment biomarkers. A systematic review applying the biological variation data critical appraisal checklist (BIVAC). Clin Chim Acta 2019;495:467-75.

36. Banfi G, Lombardi G, Colombini A, Lippi G. Bone metabolism markers in sports medicine. Sports Med 2010;40:697-714.

37. Banfi G, Colombini A, Lombardi G, Lubkowska A. Metabolic markers in sport medicine. Adv Clin Chem 2012;56:1-47.

38. Kargotich S, Goodman C, Keast D, Morton AR. The influence of exercise-induced plasma volume changes on the interpretation of biochemical parameters used for monitoring exercise, training and sport. Sports Med 1998;26:101-17.

39. Lobigs L, Sottas PE, Bourdon P, Nikolovski Z, El-Gingo M, Varamenti $E$, et al. A step towards removing plasma volume variance from the Athlete's Biological Passport: the use of 
biomarkers to describe vascular volumes from a simple blood test. Drug Test Anal 2018;10:294-300.

40. Maiorana A, O'Driscoll G, Goodman C, Taylor R, Green D. Combined aerobic and resistance exercise improves glycemic control and fitness in type 2 diabetes. Diabetes Res Clin Pract 2002;56:115-23.

41. Murray B, Rosenbloom C. Fundamentals of glycogen metabolism for coaches and athletes. Nutr Rev 2018;76:243-59.
42. World Anti-Doping Agency. Athlete biological passport operating guidelines, versión 6.0 [Online]; 2017. Available from:

https://www.wada-ama.org/sites/default/files/resources/files/ guidelines_abp_v6_2017_jan_en_final.pdf [Accessed 06 Jun 2021].

Supplementary Material: The online version of this article offers supplementary material (https://doi.org/10.1515/cclm-2021-0910). 